\title{
Characterization of $T_{1}$ bias from lipids in MOLLI and SASHA pulse sequences
}

\author{
Sarah B Thiesson*, Richard B Thompson, Kelvin Chow \\ From 18th Annual SCMR Scientific Sessions \\ Nice, France. 4-7 February 2015
}

\section{Background}

Increased myocardial $\mathrm{T}_{1}$ values are associated with fibrosis and edema, while decreased values in Fabry disease have been attributed to the short $\mathrm{T}_{1}$ of infiltrative lipids [1,2]. The relationship between lipid concentration (LC) and best-fit $\mathrm{T}_{1}$ values is unknown. This study aims to determine the dependence of MOLLI and SASHA $\mathrm{T}_{1}$ values on $\mathrm{LC}$.

MOLLI and SASHA[3] $\mathrm{T}_{1}$ mapping sequences are based on the bSSFP acquisition. bSSFP signal yield as a function of off-resonance frequency is well characterized $[4,5]$, with phase inversion in sequential "bSSFP bands" and a profile shift as a function of resonance frequency, resulting in constructive/destructive interference between water and fat $[6,7]$. We hypothesized that lipids may decrease or increase $T_{1}$ values as a function of offresonance frequency.

\section{Methods}

Bloch equation simulations of MOLLI and SASHA for $0: 2: 10 \%$ LC incorporated exact pulse sequence parameters including slice profiles and an accurate fat spectral line shape.

MOLLI and SASHA acquisitions (identical to simulations) were repeated 50 times, spanning $450 \mathrm{~Hz}$ of offresonance (1.25 bSSFP bands) in both phantoms (LC of $0.5-10 \%)$, and in-vivo in three calf muscle regions with different LC [8]. Acquisition Parameters: 1.5T Siemens

Sonata, single-shot bSSFP, $1.35 / 2.7 \mathrm{~ms}$ TE/TR, 192x72 matrix, 360x270 mm FOV, $70^{\circ}$ SASHA flip, $35^{\circ}$ MOLLI flip [9]. $\mathrm{T}_{1}$ values were calculated using standard LookLocker correction (MOLLI) or 2 and 3 parameter exponential models (SASHA) at each frequency increment across the bSSFP band.

\section{Results}

MOLLI and SASHA $T_{1}$ values have an asymmetric relationship with off-resonance, with larger positive and negative biases with larger LC (Fig. 1). Over a small \pm 45 $\mathrm{Hz}$ range, a $1 \% \mathrm{LC}$ gives rise to a $\mathrm{T}_{1}$ bias ranging from -39 to $+26 \mathrm{~ms}$ (MOLLI), -19 to $+16 \mathrm{~ms}$ (SASHA 3p) and -44 to $+25 \mathrm{~ms}$ (SASHA 2p). The location of the crossover point is a function of field-strength and TR; these findings are specific to $1.5 \mathrm{~T}$ and $\mathrm{TR}=2.7 \mathrm{~ms}$. MOLLI $\mathrm{T}_{1}$ values have an additional intrinsic dependence on offresonance resulting in an underlying domed shape [10].

\section{Conclusions}

Relatively low LC results in clinically relevant negative or positive shifts in tissue $T_{1}$ over a narrow range of offresonance frequencies with MOLLI and SASHA. Thus, increased or decreased native $T_{1}$ values can potentially be ascribed to lipids, which can confound underlying increased water $T_{1}$ values ascribed to fibrosis or edema and complicate the use of $T_{1}$ mapping for indirect identification of lipids via reduced $\mathrm{T}_{1}$ values $[1,2]$. 


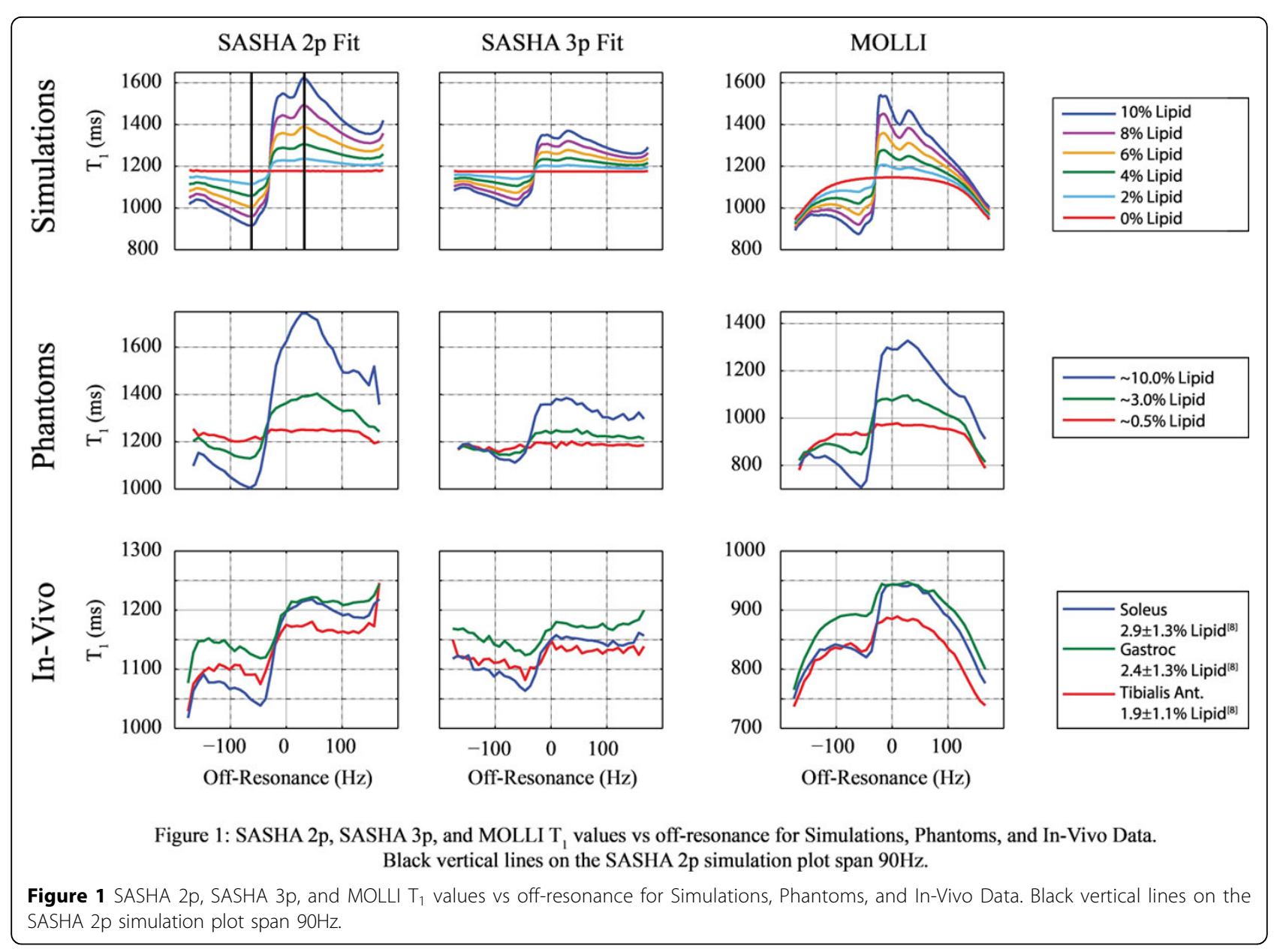

Published: 3 February 2015

\footnotetext{
References

1. Sado DM, et al: Circ Cardiovasc Imag 2013, 6:392.

2. Thompson RB, et al: Circ Cardiovasc Imag 2013, 6:637.

3. Chow K, et al: Magn Reson Med 2014, 71:2082.

4. Carr H: Phys Rev 1958, 112:1693.

5. Miller KL: Magn Reson Med 2010, 63:385.

6. Aquaro GD, et al: J Magn Reson Imag 2014, 40:126.

7. Bley TA, et al: J Magn Reson Imag 2010, 31:4.

8. Machann J, et al: Magn Reson Imag 2003, 17:350

9. Chow K, et al: JCMR 2014, 16:M9.

10. Kellman P, et al: J Cardiovasc Magn Reson 2013, 22:15.
}

doi:10.1186/1532-429X-17-S1-W10

Cite this article as: Thiesson et al:: Characterization of $\mathrm{T}_{1}$ bias from lipids

in MOLLI and SASHA pulse sequences. Journal of Cardiovascular Magnetic

Resonance 2015 17(Suppl 1):W10.

\section{Submit your next manuscript to BioMed Central} and take full advantage of:

- Convenient online submission

- Thorough peer review

- No space constraints or color figure charges

- Immediate publication on acceptance

- Inclusion in PubMed, CAS, Scopus and Google Scholar

- Research which is freely available for redistribution

Submit your manuscript at www.biomedcentral.com/submit 